\title{
Surgery for Gastrinoma and Insulinoma in Multiple Endocrine Neoplasia Type 1
}

\author{
Jeffrey A. Norton, MD, ${ }^{*}$ Tony D. Fang, MD,* and Robert T. Jensen, MD, ${ }^{\dagger}$ Stanford, California, and Bethesda, \\ Maryland
}

\section{Key Words}

Pancreatic endocrine tumor, endocrine neoplasia type 1, gastrinoma, insulinoma

\begin{abstract}
The surgical management of pancreatic endocrine tumors in patients with multiple endocrine neoplasia type 1 remains controversial. Gastrinoma and insulinoma are the 2 most common functional pancreatic neuroendocrine tumors in patients with multiple endocrine neoplasia type 1 . Gastrinomas cause gastric acid hypersecretion and peptic ulcer disease that are best managed using proton pump inhibitors. Surgery to remove the gastrinoma in patients with multiple endocrine neoplasia type 1 is seldom curative unless a more extensive Whipple pancreaticoduodenectomy is performed. Because the prognosis is excellent, aggressive resections such as a Whipple procedure are only indicated for large, locally metastatic, advanced tumors. Furthermore, surgery to remove imageable tumors that are $2 \mathrm{~cm}$ in diameter is associated with excellent outcomes and decreased probability of liver metastases. Because gastrinomas are commonly multiple and most originate in the duodenum and develop lymph node metastases, the duodenum should be opened and all tumors and lymph nodes excised. Insulinomas cause hypoglycemia that results in neuroglycopenic symptoms. Medical management of the hypoglycemia is less effective than that of the gastric acid hypersecretion. Fortunately, the insulinoma is usually clearly identified using routine pancreatic imaging studies. There is a high likelihood of cure when the insulinoma is excised surgically. However, recurrent hypoglycemia may occur, and careful follow-up is indicated. (JNCCN 2006;4:148-153)
\end{abstract}

The gene responsible for multiple endocrine neoplasia type 1 (MEN1) was identified recently. ${ }^{1} \mathrm{MEN} 1$ is diagnosed clinically in patients who have tumors in at least 2 of the following tissues: parathyroid, endocrine pancreas, and pituitary. A simple diagnostic criterion of MEN1 is a cluster of at least 2 first-degree relatives, one with a clinical diagnosis of MEN1 and the other with at least one of the endocrine tumors associated with MEN1. ${ }^{2}$

Gastrinomas (neuroendocrine tumors that secrete gastrin and cause Zollinger-Ellison syndrome [ZES]) are the most common functional neuroendocrine tumors in MEN1, ${ }^{3}$ and management of gastrinoma in patients with MEN1 has been controversial. ${ }^{4}$ Approximately $50 \%$ of patients with MEN1 develop gastrinoma by the age of 50 years. ${ }^{2}$ Gastrinomas are often multiple, originate in the duodenum, and are metastatic to adjacent lymph nodes at diagnosis; approximately $15 \%$ show aggressive growth. Medical management of the excessive gastric acid secretion, peptic ulcer disease, and diarrhea using proton pump inhibitors is very effective. The usual doses for MEN1 are twice the standard dose for peptic ulcers, given twice daily.

Studies of the effect of surgery on gastrinoma in patients with MEN1 show that it is seldom curative but can control malignant tumors and prevent liver metastases. Surgery is recommended when patients have identifiable, large $(2 \mathrm{~cm}$ in diameter) tumors that may be malignant.

Insulinoma with associated hypoglycemia is the second most common functional pancreatic neuroendocrine tumor in MEN1. Between $10 \%$ and $35 \%$ of patients with MEN1 will develop insulinoma. ${ }^{2}$ Insulinomas are commonly benign, easily identified within the pancreas on preoperative imaging, and usually not multiple. Because medical management of the hypoglycemia is seldom adequate, surgical resection is the best treatment for MEN1 insulinoma. This article details the technique, results, and rationale for different surgical procedures for patients with MEN1 who have gastrinoma or insulinoma. 
Surgery in Multiple Endocrine Neoplasia Type 1

\section{Surgical Cure Rate in Patients with Zollinger-Ellison Syndrome and MEN1}

It became clear 15 years ago that most gastrinomas in patients with MEN1 and ZES are located in the duodenum, not the pancreas. ${ }^{5,6}$ Previously, failure to identify the primary gastrinoma in the duodenum resulted in a low surgical cure rate, ${ }^{7-12}$ and some researchers suggested that routine surgical exploration for cure of ZES in MEN1 patients should not be performed. Furthermore, more recent studies (Table 1) still indicate that surgical cure is very low $(14 \%)^{13-19}$ unless a Whipple procedure (resection of the proximal pancreas and duodenum) is performed. The determination of cure requires measurement of fasting serum levels of gastrin, a secretin test that shows no increase in gastrin levels, and no tumor on postoperative imaging studies, including computed tomography (CT) and the more sensitive somatostatin receptor scintigraphy (SRS). A major criticism of the current literature is that most studies have inadequate testing and follow-up to document cure. In our experience, ${ }^{13}$ patients with MEN1 who initially appear to be cured can later experience recurrence. Recurrence is diagnosed when the secretin test shows an increase in gastrin levels before an elevated fasting serum level of gastrin or a tumor is detected on imaging studies. ${ }^{14}$ This inability to cure patients may be explained by incomplete resection of multiple small duodenal primary gastrinomas (Figure 1) and lymph node metastases. ${ }^{15}$ The surgeon may remove some of the tumors without identifying every tumor or lymph node. However, a Whipple procedure removes the entire gastrinoma triangle, including the pancreatic head, duodenum, and draining nodes. ${ }^{18}$ This procedure seems to have a higher cure rate but may also be associated with unacceptably high morbidity and mor-

\begin{tabular}{|lll|}
\hline Table 1 & $\begin{array}{l}\text { Surgical Cure Rate in } 15 \text { Series of } \\
\text { Patients With MEN1 and ZES Treated } \\
\text { With Local Resection Without Whipple } \\
\text { Pancreaticoduodenectomy }\end{array}$ \\
\hline Years & Patients, $\boldsymbol{N}$ & Cure Rate, $\boldsymbol{n}$ (\%) \\
\hline $1990-2001$ & 242 & $35(14)$ \\
\hline
\end{tabular}

Source: Data are from Gibril et al. ${ }^{3}$

tality in patients with no symptoms and expected excellent survival.

Several small series have reported excellent results with the use of Whipple resection in patients with ZES and MEN1 (Table 2). In an apparently higher proportion of cases (88\%) than with less extensive resection, Whipple pancreaticoduodenectomy has cured patients with ZES and MEN1. This finding suggests that Whipple resection increases cure rate in patients with ZES and MEN1. ${ }^{20-23}$ However, in each of these studies, serial secretin tests were not performed and recurrent ZES may have been missed. Certainly, Whipple resection is extensive and makes repeat surgery technically more difficult. These limitations are important for patients with ZES and MEN1 because patients with MEN1 may develop additional neuroendocrine tumors requiring additional surgery. Furthermore, if liver metastases develop after a Whipple resection, liver embolization cannot be used for treatment $\mathrm{t}^{24,25}$ because of a high risk for ascending cholangitis and liver abscess. However, we believe that Whipple resection does have a role in select patients. It is recommended for younger patients with MEN1/ZES who have a large $(>3 \mathrm{~cm})$ pancreatic head or duodenal tumor that cannot be enucleated
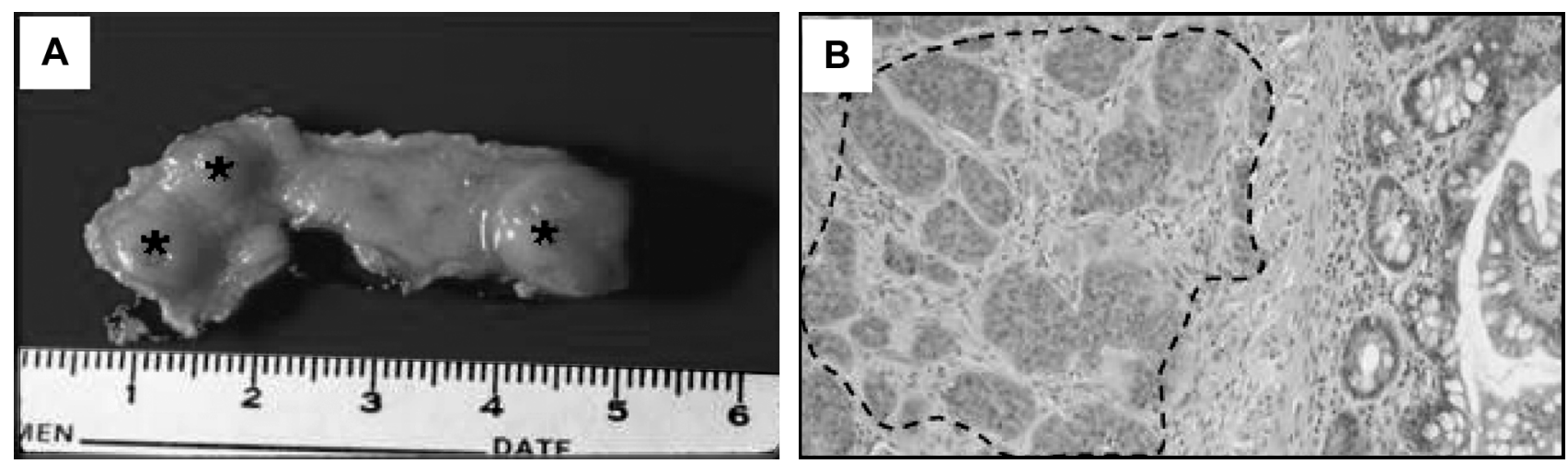

Figure 1 Multiple primary gastrinomas in the duodenum of a patient with multiple endocrine neoplasia type 1 (MEN1). (A) Surgical specimen shows 3 primary duodenal gastrinomas (*). (B) Microscopic examination shows a neuroendocrine tumor in the submucosa of the duodenum (dotted area). 
Norton et al.

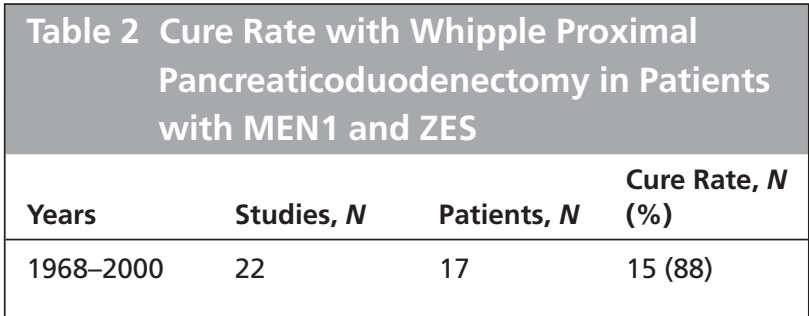

Source: Data are from Gibril et al. ${ }^{3}$

(Figure 2) or multiple peripancreatic head lymph nodes and a duodenal or pancreatic head primary tumor. Whipple resection is also recommended for patients who are not cured after a duodenal or pancreatic head tumor with or without lymph node metastases is removed using local resection., ${ }^{4,17-20}$ Whipple resection is currently not recommended for "routine" patients with multiple small duodenal gastrinomas with or without lymph node metastases. Instead, enucleation or resection of these tumors should be attempted.

\section{Routine Surgical Exploration in Patients with ZES and MEN1}

As described previously, recent evidence shows that cure seldom occurs in ZES patients with MEN1. Whether routine surgical exploration should be performed in patients with ZES and MEN1 is controversial..$^{24-34}$ Several groups recommend routine surgical exploration to decrease the probability of malignant spread. ${ }^{31}$ The operation includes distal pancreatectomy; intraoperative ultrasound and enucleation of tumors in the pancreatic head; duodenotomy; and removal of duodenal tumors, peripancreatic lymph nodes, and lymph nodes along the celiac trunk and hepatic ligament. ${ }^{4,32}$ In contrast, other groups recommend that surgical exploration only be performed when a tumor of 2 to $3 \mathrm{~cm}$ is imaged. ${ }^{33,35}$ Opening the duodenum to remove small tumors and regional lymph nodes is performed during the procedure. Researchers disagree on not only when surgical exploration should be performed but also what operation, with differences primarily in whether distal pancreatectomy should be performed routinely. ${ }^{34-37}$ Distal pancreatectomy may remove additional microscopic tumors or islet cell hyperplasia. However, these pathologic findings may be clinically insignificant and the total amount of pancreatic mass will decrease, predisposing the patient to pancreatic exocrine and endocrine insufficiency. Furthermore, a prior distal pancreatectomy may hinder the subsequent ability to completely resect new pancreatic head tumors using a Whipple procedure. Lastly, our recent studies show ${ }^{26}$ that no patients with MEN1/ZES who had intrapancreatic tumors enucleated without routine distal pancreatectomy subsequently developed liver metastases.

This inability to agree on the best operation has occurred for several reasons. First, no controlled studies with adequate follow-up have included sufficient numbers of patients with MEN1/ZES to clearly determine the best procedure. Second, these patients do very well. In fact, their long-term survival is better than a similar cohort of patients with sporadic ZES. Even in the worst-case scenario, when patients have distant metastatic disease, the 15-year survival rate is $52 \%{ }^{38}$ Furthermore, the long-term outcome of patients with MEN1/ZES in the current era of satisfactory treatment
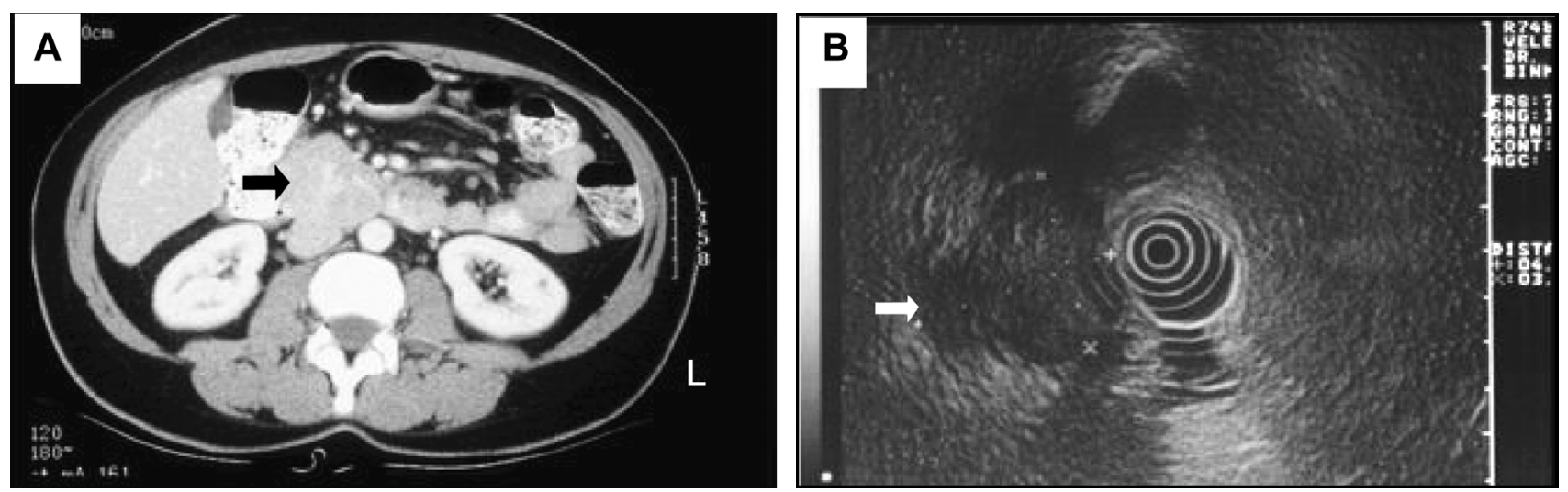

Figure 2 Patient with multiple endocrine neoplasia type 1 (MEN 1) and a large locally advanced gastrinoma in the head of pancreas treated using Whipple pancreaticoduodenectomy. (A) Pancreatic computed tomography shows a 6-cm hypervascular mass (black arrow) in the head of the pancreas. (B) Endoscopic ultrasound shows the same hypoechoic mass (white arrow). 
Surgery in Multiple Endocrine Neoplasia Type 1

of the parathyroid and pituitary disease is largely unknown. When patients die of metastatic neuroendocrine tumors, ${ }^{38-44}$ gastrinoma may or may not be the cause. Patients may also have another pancreatic neuroendocrine tumor or other malignant neuroendocrine tumors, such as a bronchial, thymic, or gastric carcinoid. ${ }^{43,44}$ However, some recent studies indicate that the gastrinoma and other pancreatic neuroendocrine tumors are the critical determinants of long-term survival. ${ }^{45-47}$

We believe this strongly indicates that imageable large pancreatic neuroendocrine tumors in patients with MEN1 should be removed surgically. This recommendation is based on results from numerous studies that show a strong correlation between primary tumor size and the development of liver metastases, which are the primary determinants of long-term survival in patients with pancreatic neuroendocrine tumors. ${ }^{27,33,38,48}$ Furthermore, $23 \%$ of these pancreatic neuroendocrine tumors have demonstrated aggressive growth and hepatic metastases. ${ }^{44,47}$ Nearly $40 \%$ of patients with aggressive neuroendocrine tumors die from tumor, which is greater than the mortality rate for patients with nonaggressive pancreatic neuroendocrine tumors. Most (50\%-70\%) patients with MEN1 and imageable neuroendocrine tumors of the pancreas $(2-3 \mathrm{~cm})$ who underwent surgical exploration had lymph node but not liver metastases. ${ }^{47}$ Some researchers have interpreted this finding as support for earlier exploration when tumors are smaller. ${ }^{13,29}$ However, we think the primary indication for exploration at that time is to avoid liver metastases. Fourth, in a recent study involving 81 patients ${ }^{26}$ with MEN1/ZES, the 15-year survival rates were $100 \%$ in 25 patients without surgery when pancreatic neuroendocrine tumors were smaller than $2.5 \mathrm{~cm} ; 100 \%$ in 17 patients with surgical resection of a single pancreatic neuroendocrine tumor that was less than 6 $\mathrm{cm}$; and $89 \%$ in 31 patients with multiple tumors 2 $\mathrm{cm}$ or larger or a single tumor larger than $6 \mathrm{~cm}$ tumor (with surgery). Distal pancreatectomy was not routinely performed, which suggests it is not necessary. ${ }^{26}$

Table 3 Surgical Cure Rate in Patients with MEN1 and Insulinoma

\begin{tabular}{|llll|}
\hline Patients, $\boldsymbol{N}$ & $\begin{array}{l}\text { CT-Imageable } \\
\text { Insulinoma, } \\
\boldsymbol{n}(\%)\end{array}$ & $\begin{array}{l}\text { Cure Rate, } \\
\boldsymbol{n ( \% )}\end{array}$ & $\begin{array}{l}\text { Recurrence, } \boldsymbol{n} \\
(\%) /(\text { time to } \\
\text { recurrence) }\end{array}$ \\
\hline 7 & $7(100)$ & $6(86)$ & $1(14) /(5 \mathrm{y})$ \\
\hline
\end{tabular}

Currently, the only reliable clinical marker that allows prediction of the aggressiveness of a pancreatic neuroendocrine tumor in a patient with ZES and MEN1 is tumor size. ${ }^{27,38,48}$ The most important variable that affects survival in patients with MEN1 and gastrinoma is liver metastases..$^{27,38,48}$ Studies have shown that in gastrinomas and other pancreatic neuroendocrine tumors, primary tumor size is highly predictive of the development of liver metastases. ${ }^{27,38,48}$ Therefore, because patients with ZES/MEN1 are seldom cured by surgery, patients with tumors $2 \mathrm{~cm}$ or smaller have a 100\% 15year survival rate, and patients with larger tumors have an increased probability of developing liver metastases, we recommend surgical resection of imageable tumors that are $2 \mathrm{~cm}$ or greater. A distal pancreatectomy should not be routinely performed unless the imageable tumor is in the tail of the pancreas. Surgery should focus on removal of the imageable tumor. If the imageable tumor is in the head of the pancreas, enucleation is recommended, if technically feasible. This procedure may not be feasible when the tumor abuts the pancreatic duct or common bile duct. If the imageable tumor is in the tail, distal pancreatectomy is preferred because it decreases the complication of pancreatic duct leak.

In addition, the surgeon should open the duodenum in patients with ZES to identify and remove small duodenal gastrinomas (Figure 1). These are usually multiple and frequently spread to adjacent lymph nodes; the surgeon should perform extensive lymph node sampling around the head of the pancreas. If tumors in the pancreatic head area are very large and multiple localized lymph node metastases are present (Figure 2), the surgeon should perform a Whipple procedure. This approach should increase the probability of long-term survival because it reduces the likelihood of liver metastases. ${ }^{49}$

\section{Surgical Management of Insulinoma in MEN1}

Insulinoma is the second most common functional pancreatic neuroendocrine tumor in patients with MEN1.50 It occurs in approximately $10 \%$ to $35 \%$ of cases $^{2}$ and causes severe neuroglycopenic symptoms secondary to hypoglycemia. Unlike gastrinoma, the symptoms are poorly controlled medically, but, fortunately, successful surgical resection of insulinoma in patients with MEN1 usually leads to complete amelioration of the hypoglycemia..$^{50-54}$ This result occurs despite the fact that 
Norton et al.

pathologic analyses of the resected pancreas from patients with MEN1 show that most have multicentric neuroendocrine tumors. ${ }^{55}$ However, clinical studies suggest that in MEN1 insulinoma, patients have a dominant pancreatic neuroendocrine tumor that can be clearly identified on conventional imaging studies such as CT, magnetic resonance imaging, and endoscopic ultrasound (Figure 3). ${ }^{50-53}$ The tumor identified by imaging is most likely the insulin-secreting tumor, and the surgery should be designed to remove it. In studies of patients with MEN1 insulinoma, ${ }^{51,53,54}$ removal of a clearly identified tumor has resulted in complete amelioration of the hypoglycemia in nearly every patient (Table 3 ). These tumors have not been subtle and are usually approximately 2 to $3 \mathrm{~cm}$ in diameter (Figure 3). These features are different from sporadic insulinomas that are usually more occult and measure approximately $1 \mathrm{~cm}$ in diameter. ${ }^{56}$ Surgery should focus on excision of the preoperatively identified tumor. If the tumor is in the head of the pancreas, enucleation is preferred over Whipple resection. Intraoperative ultrasound is used during the surgery to facilitate tumor identification and removal (Figure 3). If the tumor is identified in the pancreatic tail, distal
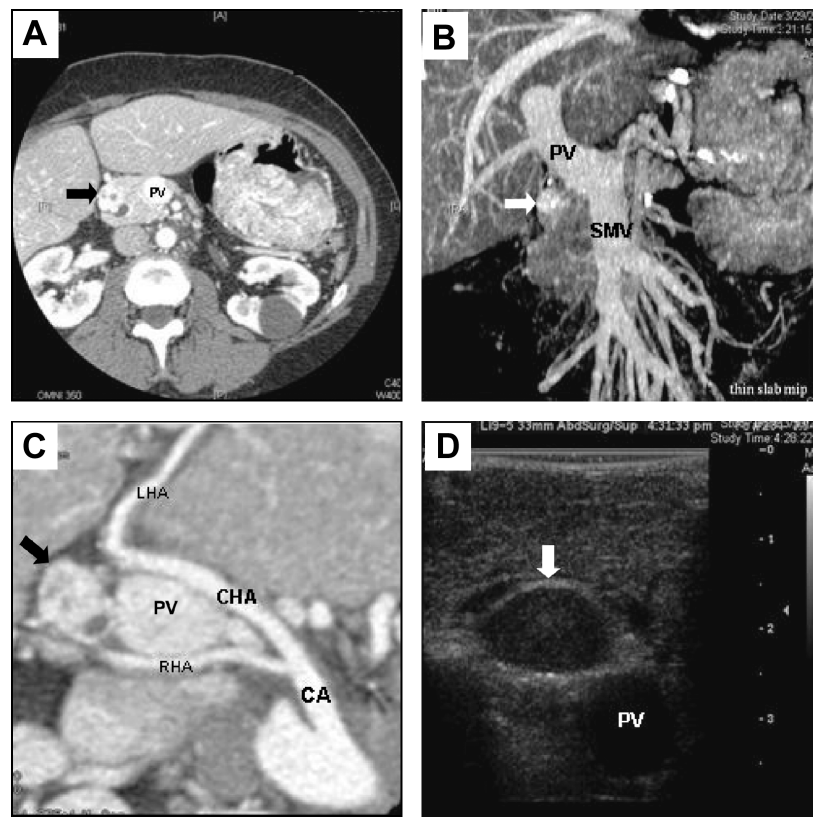

Figure 3 Multiple endocrine neoplasia type 1 (MEN1) and a 2-cm insulinoma in the head of pancreas. This small tumor was treated by enucleation. Pancreatic computed tomography scans with 3-dimensional reconstruction show (A) axial arterial phase; (B) coronal reconstruction; and (C) sagittal reconstruction. (D) Intraoperative ultrasound. The black arrows indicate insulinoma. Abbreviations: PV, portal vein; SMV, superior mesenteric vein; CA, celiac axis; CHA, common hepatic artery; LHA, left hepatic artery; RHA, right hepatic artery. pancreatectomy is preferred. Our initial cure rate has been very high (100\%), with recurrent hypoglycemia occurring in only 1 of 7 patients (14\%). Thus, the clinical syndrome of insulinoma in patients with MEN1 is a clear indication for surgery, and the surgery has a high probability of success. In the rare patient who has an insulinoma with multiple small tumors throughout the pancreas on preoperative imaging studies, or for whom no tumor is seen on imaging, the surgeon should consider venous insulin sampling using either portal venous or hepatic vein sampling after selective intra-arterial calcium injections..$^{51,56}$

\section{References}

1. Chandrasekharappa SC, Guru SC, Manickam P, et al. Positional cloning of the gene for multiple endocrine neoplasia-type 1. Science 1997;276:404-407.

2. Schussheim DH, Skarulis MC, Agarwal SK, et al. Multiple endocrine neoplasia type 1: new clinical and basic findings. Trends Endocrinol Metab 2001;12:173-178.

3. Gibril F, SchumannM, Pace A, Jensen RT. Zollinger-Ellison syndrome and multiple endocrine neoplasia type 1 (MEN1): a prospective NIH study of 107 patients and comparison with 1009 patients from the literature. Medicine 2004;83:43-83.

4. Norton JA, Jensen RT. Resolved and unresolved controversies in the surgical management of patients with Zollinger-Ellison syndrome. Ann Surg 2004;240:757-773.

5. Pipeleers-Marichal M, Somers G, Willems G, et al. Gastrinomas in the duodenums of patients with multiple endocrine neoplasia type 1 and the Zollinger-Ellison syndrome. N Engl J Med.1990;322: 723-727.

6. Thompson NW, Vinik AI, Eckhauser FE. Microgastrinomas of the duodenum. A cause of failed operations for the Zollinger-Ellison syndrome. Ann Surg 1989;209:396-404.

7. vanHeerden JA, Smith SL, Miller LJ. Management of the ZollingerEllison syndrome in patients with multiple endocrine neoplasia type 1. Surgery 1986;100:971-977.

8. Deveney CW, Deveney KS, Stark D, et al. Resection of gastrinomas. Ann Surg 1983;198:546-553.

9. Jensen RT, Gardner JD, Raufman JP, et al. Zollinger-Ellison syndrome: current concepts and management. Ann Intern Med 1983;98:59-75.

10. Malagelada JR, Edis AJ, Adson MA, et al. Medical and surgical options in the management of patients with gastrinoma. Gastroenterology 1983;84:1524-1532.

11. Stabile BE, Morrow DJ, Passaro E Jr. The gastrinoma triangle: operative implications. Am J Surg 1984;147:25-31.

12. Thompson JC, Lewis BG, Wiener I, et al. The role of surgery in the Zollinger-Ellison syndrome. Ann Surg 1983;197:594-607.

13. Norton JA, Fraker DL, Alexander HR, et al. Surgery to cure the Zollinger-Ellison syndrome. N Engl J Med 1999;341:635-644.

14. Fishbeyn VA, Norton JA, Benya RV, et al. Assessment and prediction of long-term cure in patients with the Zollinger-Ellison syndrome: the best approach. Ann Intern Med 1993;119:199-206.

15. MacFarlane MP, Fraker DL, Alexander HR, et al. A prospective study of surgical resection of duodenal and pancreatic gastrinomas in multiple endocrine neoplasia-type 1. Surgery 1995;118:973-980. 
Surgery in Multiple Endocrine Neoplasia Type 1

16. Norton JA, Doppman JL, Jensen RT. Curative resection in ZollingerEllison syndrome: results of a 10-year prospective study. Ann Surg 1992;215:8-18.

17. Howard TJ, Zinner MJ, Stabile BE, et al. Gastrinoma excision for cure. A prospective analysis. Ann Surg 1990;211:9-14.

18. Norton JA, Jensen RT. Current surgical management of ZollingerEllison syndrome (ZES) in patients without multiple endocrine neoplasia-type 1 (MEN1). Surg Oncol 2003;12:145-151.

19. Norton JA. Neuroendocrine tumors of the pancreas and duodenum. Curr Probl Surg 1994;31:77-156.

20. Stabile BE, Passaro Jr E. Benign and malignant gastrinoma. Am J Surg 1985;49:144-150.

21. Stadil F. Treatment of gastrinomas with pancreaticoduodenectomy. In: Mignon M, Jensen RT, eds. Endocrine tumors of the pancreas: recent advances in research and management. Series: Frontiers in Gastrointestinal Research. Basel, Switzerland: S. Karger, 1995:333-341.

22. Delcore R, Friesen SR. Role of pancreatoduodenectomy in the management of primary duodenal wall gastrinomas in patients with Zollinger-Ellison syndrome. Surgery 1992;112:1016-1022.

23. Imamura $M$, Kanda M, Takahashi K, et al. Clinicopathological characteristics of duodenal microgastrinomas. World J Surg 1992; 16:703-709

24. Ruszniewski P, Malka D. Hepatic arterial chemoembolization in the management of advanced digestive endocrine tumors. Digestion 2000;62:79-83.

25. Ruszniewski P, Rougier P, Roche A, et al. Hepatic arterial chemoembolization in patients with liver metastases of endocrine tumors. A prospective phase II study in 24 patients. Cancer 1993;71:2624-2630.

26. Norton JA, Alexander HR, Fraker DL, et al. Comparison of surgical results in patients with advanced and limited disease with multiple endocrine neoplasia type 1 and Zollinger-Ellison syndrome. Ann Surg 2001;234:495-506.

27. Cadiot G, Vuagnat A, Doukhan I, et al. Prognostic factors in patients with Zollinger-Ellison syndrome and multiple endocrine neoplasia type 1. Gastroenterology 1999;116:286-293.

28. Wells Jr SA. Surgery for the Zollinger-Ellison syndrome. N Engl J Med 1999;341:689-690.

29. Skogseid B, Oberg K, Eriksson B, et al. Surgery for asymptomatic pancreatic lesion in multiple endocrine neoplasia type 1. World J Surg 1996;20:872-877.

30. Grama D, Eriksson B, Martensson H, et al. Clinical characteristics, treatment and survival in patients with pancreatic tumors causing hormonal syndromes. World J Surg 1992;16:632-639.

31. Thompson NW. Management of pancreatic endocrine tumors in patients with multiple endocrine neoplasia type 1 . Surg Oncol Clin N Am 1998;7:881-891.

32. Brandi ML, Gagel RF, Angeli A, et al. Guidelines for diagnosis and therapy of MEN type 1 and type 2. J Clin Endocrinol Metab 2001;86: 5658-5671.

33. Lowney JK, Frisella MM, Lairmore TC, et al. Pancreatic islet cell tumor metastasis in multiple endocrine neoplasia type 1: correlation with primary tumor size. Surgery 1999;125:1043-1049.

34. Thompson NW. Current concepts in the surgical management of multiple endocrine neoplasia type 1 pancreatic-duodenal disease. Results in the treatment of 40 patients with Zollinger-Ellison syndrome, hypoglycaemia or both. J Intern Med 1998;243:495-500.

35. Jensen RT. Zollinger-Ellison syndrome. In: Doherty GM, Skogseid B, eds. Surgical Endocrinology: Clinical Syndromes. Philadelphia: Lippincott Williams \& Wilkins; 2001:291-344.
36. Thompson NW. Multiple endocrine neoplasia type I. Surgical therapy. Cancer Treat Res 1997;89:407-419.

37. Bartsch DK, Langer $\mathrm{P}$, Wild A, et al. Pancreaticoduodenal endocrine tumors in multiple endocrine neoplasia type 1: surgery or surveillance? Surgery 2000;128:958-966.

38. Weber HC, Venzon DJ, Lin JT, et al. Determinants of metastatic rate and survival in patients with Zollinger-Ellison syndrome: a prospective long-term study. Gastroenterology 1995;108:1637-1649.

39. Jensen RT. Management of the Zollinger-Ellison syndrome in patients with multiple endocrine neoplasia type 1. J Intern Med 1998;243: 477-488.

40. Doherty GM, Olson JA, Frisella MM, et al. Lethality of multiple endocrine neoplasia type I. World J Surg 1998;22:581-587.

41. Shepherd JJ. The natural history of multiple endocrine neoplasia type I. Highly uncommon or highly unrecognized. Arch Surg 1991; 126:935-952.

42. Shepherd JJ, Challis DR, Davies PF, et al. Multiple endocrine neoplasm, type 1: gastrinomas, pancreatic neoplasms, microcarcinoids, the Zollinger-Ellison syndrome, lymph nodes, and hepatic metastases. Arch Surg 1993;128:1133-1142.

43. Gibril F, Chen Y-J, Schrump DS, et al. Prospective study of thymic carcinoids in patients with multiple endocrine neoplasia type 1. J Clin Endocrinol Metab 2003;88:1066-1081.

44. Bordi C, Falchetti A, Azzoni C, et al. Aggressive forms of gastric neuroendocrine tumors in multiple endocrine neoplasia type I. Am J Surg Pathol 1997;21:1075-1082.

45. Dean PG, vanHeerden JA, Farley DR, et al. Are patients with multiple endocrine neoplasia type I prone to premature death? World J Surg 2000;24:1437-1441.

46. Wilkinson S, Teh BT, Davey KR, et al. Cause of death in multiple endocrine neoplasia type 1. Arch Surg 1993;128:683-690.

47. Gibril F, Venzon DJ, Ojeaburu JV, et al. Prospective study of the natural history of gastrinoma in patients with MEN1: Definition of an aggressive and a nonaggressive form. J Clin Endocrinol Metab 2001;86:5282-5293.

48. Yu F, Venzon D, Serrano J, et al. Propsective study of the clinical course, prognostic factors and survival in patients with longstanding Zollinger-Ellison syndrome. J Clin Oncol 1999;17:615-630.

49. Fraker DL, Norton JA, Alexander HR, et al. Surgery in ZollingerEllison syndrome alters the natural history of gastrinoma. Ann Surg 1994;220:320-330.

50. Doherty GM. Multiple endocrine neoplasia type 1. J Surg Oncol 2005;89:143-148.

51. Sheppard BC, Norton JA, Doppman JL, et al. Management of islet cell tumors in patients with multiple endocrine neoplasia: a prospective study. Surgery 1989;106:1108-1118.

52. Marx SJ, Agarwal SK, Kester MB, et al. Multiple endocrine neoplasia type 1: clinical and genetic features of hereditary neoplasias. Recent Prog Horm Res 1999;54:397-438.

53. Rasbach DA, van Heerden JA, Telander RL, et al. Surgical management of hyperinsulinism in the multiple endocrine neoplasia type 1 syndrome. Arch Surg 1985;120:584-589.

54. van Heerden JA, Edis AJ, Service FJ, et al. The surgical aspects of insulinomas. Ann Surg 1979;18:677-682.

55. Gumbs AA, Moore PS, Falconi M, et al. Review of the clinical, histological, and molecular aspects of pancreatic endocrine neoplasms. J Surg Oncol 2002;81:45-53.

56. Hiramoto JS, Feldstein VA, Laberge JM, Norton JA. Intraoperative ultrasound and preoperative localization detects all occult insulinomas. Arch Surg 2001;136:1020-1025. 